\title{
Acute Myelomonocytic Leukemia in a Patient with Multiple Myeloma: Evidence for Different Clonal Origin
}

\author{
Kazunori Nakase, Kota Tsuji, Masaki Hasegawa, Yoshinori Suzuki, \\ Shigehisa TAMAKI, Motoaki Tanigawa, Takeshi IkedA and Eiki MiYANishi
}

\begin{abstract}
A case of 77-year-old female with multiple myeloma (IgG-k) developed acute myelomonocytic leukemia (AMMoL) following a myelodysplastic stage after chemotherapy with melphalancyclophosphamide combinations for 6 years. The leukemic blast cells expressed both myeloid antigens (CD11b, CD13, CD14, CD15, CD33 and CD34) and T/B lymphoid antigens (CD2, CD4, CD22 and PCA1). Cytogenetic analysis revealed a chromosome deletion -7. Analysis of immunoglobulin genes showed the heavy chain genes in germ line configuration. These findings indicate that the AMMoL was a therapy-related stem cell leukemia and was a clonal origin genetically different from multiple myeloma irrespective of plasma cell phenotype.

(Internal Medicine 34: 546-549, 1995)
\end{abstract}

Key words: therapy-related leukemia, monosomy 7

\section{Introduction}

Multiple myeloma and acute myelomonocytic leukemia (AMMoL) are generally considered to be unrelated diseases. However, several cases of coexistence of multiple myeloma and $\mathrm{AMMoL}(1,2)$ or multiple myeloma terminating in $\mathrm{AMMoL}$ $(3,4)$ have been previously described. It is known that BALB/ $\mathrm{c}$ mice develop plasmacytoma or AMMoL by injecting mineral oil into the peritoneal cavity (5). Whether these two diseases arise from same or different clonal origins is controversial. Recently, Akashi et al (6) reported the presence of two identical rearrangement bands of immunoglobulin heavy chain gene in both myeloma cells and AMMoL cells and described the involvement of common leukemic progenitors providing both myeloma and AMMoL cells. Here, we describe a case of multiple myeloma developing AMMoL which was considered to be a genetically different clone from myeloma.

\section{Patient and Methods}

\section{Case report}

A 77-year-old female was admitted to our hospital in October, 1982 because of lumbago. Peripheral blood showed a slight anemia and erythrocyte sedimentation ratio was as high as 81 $\mathrm{mm}$ per hour. The serum level of total protein was increased to $10 \mathrm{~g} / \mathrm{dl}$. Serum $\mathrm{IgG}$ was $6,750 \mathrm{mg} / \mathrm{dl}$ and the other immu- noglobulin classes were markedly depressed. Serum immunoelectrophoresis showed a monoclonal IgG-k bow. The bone marrow was hypercellular with $78.9 \%$ atypical plasma cells (Fig. 1). A diagnosis of multiple myeloma was made and the patient was treated with daily oral melphalan (2-6 mg/day, a total dose of $694 \mathrm{mg}$ ) with or without added prednisolone (10 $\mathrm{mg} /$ day) until February 1987. Following this, she also received daily oral cyclophosphamide $(50 \mathrm{mg} /$ day, a total dose of 14,200 $\mathrm{mg}$ ) and prednisolone (5-10 mg/day). In October 1988, she developed a pancytopenia with white blood cell of $900 / \mathrm{cmm}$, red blood cell of $153 \times 10^{4} / \mathrm{cmm}$ and platelet of $0.9 \times 10^{4} / \mathrm{cmm}$. The bone marrow puncture revealed a nuclear cell count of $12.6 \times 10^{4} / \mathrm{cmm}$ with the appearance of $7.2 \%$ myeloid blastic cells and plasma cells were decreased to $1.6 \%$. We ceased cyclophosphamide and prednisolone treatments and observed her with no chemotherapy. This myelodysplastic stage continued until April 1989, when the white blood cell count rapidly increased to $15,200 / \mathrm{cmm}$ with $27 \%$ monocytoid cells and $13 \%$ myeloid blastic cells. Monoblasts accounted for $20 \%$ and myeloblasts for $62 \%$ of all the nucleated cells in the bone marrow (Table 1), and a diagnosis of acute myelomonocytic leukemia was made (Fig. 2). Though there was an absence of atypical plasma cells, serum immunoelectrophoresis showed a faint band in the IgG-k region. Treatment with low-dose cytarabin was not effective and she died on December 23, 1989. Autopsy was not done. 


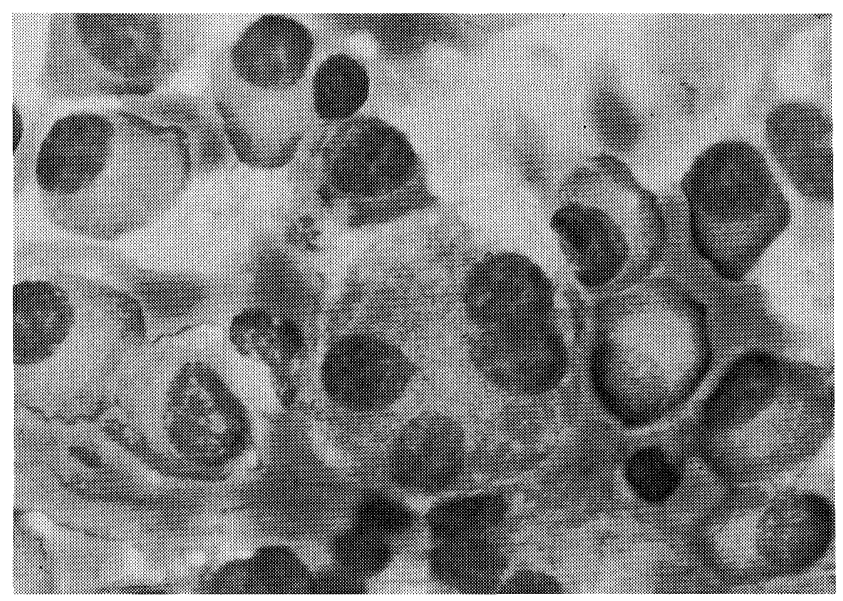

Figure 1. Myeloma cells in bone marrow (May-Giemsa staining, $\times 600)$.

Table 1. Hematological Findings on the Occurrence of AMMoL

\begin{tabular}{lrr}
\hline & $\begin{array}{c}\text { Peripheral blood } \\
(\%)\end{array}$ & $\begin{array}{c}\text { Bone marrow } \\
(\%)\end{array}$ \\
\hline Myeloblast & 13 & 62 \\
Promyelocyte & 0 & 1 \\
Myelocyte & 0 & 2 \\
Metamyelocyte & 0 & 5 \\
Neutrophil-stab & 34 & 6 \\
Neutrophil-seg & 18 & 2 \\
Eosinophil & 0 & 0 \\
Basophil & 0 & 0 \\
Monocytoid cell & 27 & 20 \\
Lymphocyte & 8 & 1 \\
Erythroblast & 0 & 480,000 \\
& & \\
Nuclear cell count & 15,200 & \\
$\quad$ (/cmm) & &
\end{tabular}

\section{Cell characterization}

Immunophenotyping. Mononuclear cells were obtained from peripheral blood by Ficoll-Hypaque density gradient centrifugation and applied for the following studies. These collected mononuclear cells consisted of over $90 \%$ leukemic cells on the cytospin preparation. Surface marker analysis was performed by the indirect immunofluorescence method as previously described (7). Before immunostaining, the cells were treated with $5 \%$ heat aggregated human $\mathrm{AB}$ serum for blocking of binding due to receptors for the IgG Fc portion. CD11b (recognized by OKM1), CD13(MCS2), CD14(My4), CD15(LeuM1), CD33 (My9), CD34 (My10) and CD41 (J15) were tested as myeloid markers; CD2 (T11), CD3 (Leu4), CD4 (Leu3), CD7 (Tp40) and CD8 (Leu2) as T-cell markers; CD10 (J5), CD19

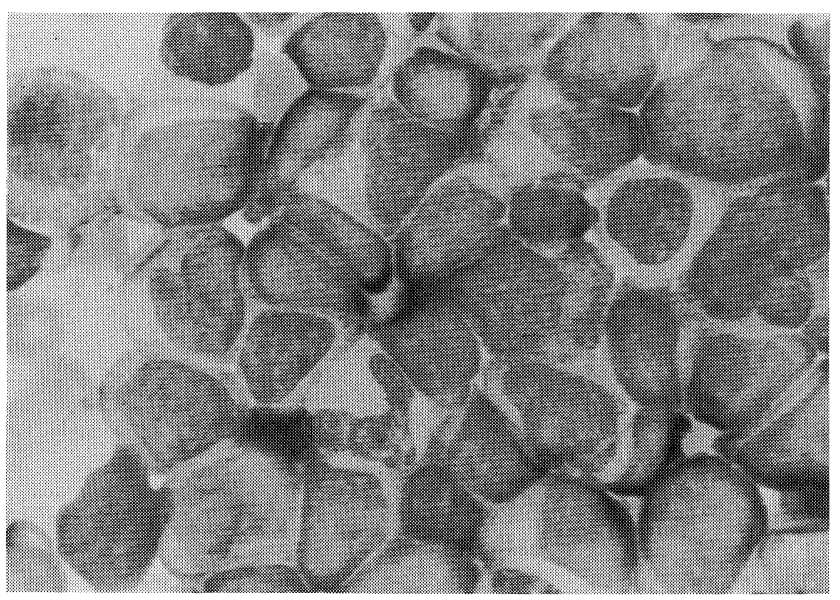

Figure 2. AMMoL cells in bone marrow (May-Giemsa staining, $\times 600)$.

(Leu12), CD20 (B1), CD22 (Leu14) and PCA1 as B-cell markers. CD38 and HLA-DR were detected by Leu17 and OKIa1, respectively. Anti-Tac was used to detect interleukin2 receptor alpha chain (CD25). Specimens were evaluated by flow cytometry (Cytron; Ortho Diagnostic Systems, Tokyo, Japan). We focused on the blastic fraction of the cytogram to clarify the phenotype of the leukemic cells. Specimens were considered positive for a monoclonal antibody (MoAb) if more than $15 \%$ of the cells showed specific labeling above the level of the control. Contaminated T-cells or B-cells were judged by considering the expression of T-cell antigen, CD3 or B-cell antigen, CD20. In fact, the contaminated T-cells or B-cells made up less than $4 \%$ of the leukemic cells.

DNA study. Southern blot analysis was performed as described previously (8). DNA probe was JH for Ig heavy chain (IgH) genes.

Cytogenetic anaysis. A chromosome study was performed on aspirated bone marrow cells as previously described (9).

\section{Results}

\section{Cellular characteristics}

The leukemic cells morphologically consisted of both myeloid blastic cells and monocytoid cells (Fig. 2), and were cytochemically stained for myeloperoxidase and alpha-naphthyl butyrate esterase. Immunophenotypic studies showed that the leukemic cells were positive for CD11b, CD13, CD14, CD15, CD33, CD34, CD2, CD4, CD22, PCA1, CD38, HLADR and CD25 (Table 2). The IgH genes were germ line configuration. Cytogenetic analysis of marrow cells revealed a complex abnormality of $45 \mathrm{XX},-7,12 \mathrm{q}-, 21 \mathrm{q}+$ in 19 of 20 metaphases. The remaining one metaphase was normal karyotype.

\section{Discussion}

In this study, we report the development of AMMoL in a 
Table 2. Surface Markers

\begin{tabular}{|c|c|}
\hline Immunophenotype & $\begin{array}{l}\text { Positive } \\
\text { cells }(\%)\end{array}$ \\
\hline \multicolumn{2}{|l|}{ Myeloid } \\
\hline $\mathrm{CD} 11 \mathrm{~b}$ & 19 \\
\hline CD13 & 54 \\
\hline CD14 & 0 \\
\hline CD15 & 7 \\
\hline CD33 & 45 \\
\hline CD34 & 70 \\
\hline CD41 & 0 \\
\hline \multicolumn{2}{|l|}{ T-lymphoid } \\
\hline $\mathrm{CD} 2$ & 18 \\
\hline CD3 & 0 \\
\hline CD4 & 28 \\
\hline CD7 & 3 \\
\hline $\mathrm{CD} 8$ & 0 \\
\hline \multicolumn{2}{|l|}{ B-lymphoid } \\
\hline CD10 & 2 \\
\hline CD19 & 0 \\
\hline $\mathrm{CD} 20$ & 4 \\
\hline CD22 & 39 \\
\hline PCA1 & 15 \\
\hline \multicolumn{2}{|l|}{ Others } \\
\hline CD25 & 18 \\
\hline CD38 & 85 \\
\hline HLA-DR & 95 \\
\hline
\end{tabular}

patient after long-term (6 years) alkylating therapy for multiple myeloma. The occurrence of AMMoL supervening on multiple myeloma following alkylating therapy is well recognized (10, 11). The patient had a myelodysplastic stage prior to AMMoL and showed a karyotype of -7 abnormality. Monosomy 7 is well recognized to be seen in secondary leukemia (12). Therefore, it is suggested that the current case was therapy-related secondary leukemia (13). There have been various descriptions of the relationship between multiple myeloma and AMMoL. Some investigators described myeloma cells with monocytic features such as phagocytosis (14) or myelomonocytic antigen expression (15). Synchronous or metachronous coexistence of myeloma and AMMoL irrespective of prior therapy was also reported $(1-4)$. This situation resembles biphenotypic or bilineal subtypes of immature acute leukemia and such leukemia cells are considered to have originated from multipotential stem cells (16). In fact, Akashi et al (6) showed the identical IgH gene rearrangements in both AMMoL cells and myeloma cells, and described the involvement of common leukemic progenitors. In addition, other investigators reported multiple myeloma cells expressing surface markers of multiple hematopoietic-cell lineages (17). However, genetically myeloma cells have rearranged genes of not only IgH but also Ig light chain, suggesting that myeloma cells originated from early B-cells or more differentiated cells (18). Therefore, concerning neoplastic target cells of multiple myeloma, further investigations are needed.

In the present case, when AMMoL occurred, a faint IgG-k monoclonal protein was still recognized, indicating the coexistence of occult neoplastic plasma cells producing IgG-k. However, unlike the case of Akashi et al (6), monoclonal IgH gene rearrangement was not detected in the AMMoL cells of our case. These AMMoL cells possessed, in addition to myeloid antigens, stem cell antigen CD34 and T/B lymphoid antigens such as CD2, CD4, CD22 and PCA1. CD25 expression is also an immature characteristic (19). Though PCA1 is a plasma cell phenotype, it is known to be rarely expressed even on myeloid lineage cells (20). Therefore, the AMMoL cells may be derived from primitive stem cells capable of both lymphoid and myeloid differentiation. In conclusion, as mentioned above, we regard the AMMoL as a therapy-induced secondary leukemia which had immature properties and was of a different clonal origin than multiple myeloma. Genetically, few cases have been proved to be different clonal diseases in the disorder like the present case. In the coexistence of AMMoL and myeloma, whether two diseases are derived from identical or different clones may be considered to vary from case to case. However, since we do not know the genetic marker expressed prior to the Ig gene rearrangement, further studies are necessary to precisely clarify the clonality of this type of disease.

Acknowledgements: We thank Drs T. Uchiyama, R. Ueda and E. Tatsumi for providing monoclonal antibodies. We thank Miss Ogura for preparing the manuscript.

\section{References}

1) Tursz T, Flandrin G, Brouet J-C, Briere J, Seligmann M. Simultaneous occurrence of acute myeloblastic leukemia and multiple myeloma without previous therapy. Br Med J 22: 642, 1974.

2) Matsuzaki M, Yamaguchi $\mathrm{K}$, Hara $\mathrm{H}$, et al. Simultaneous occurrence of acute myelogenous leukaemia and multiple myeloma without previous chemotherapy. Scand J Haematol 30: 278, 1983.

3) Kyle RA, Pierre RV, Bayrd ED. Multiple myeloma and acute myelomonocytic leukemia; Report of four cases possibly related to melphalan. N Engl J Med 283: 1121, 1970.

4) Stewart AK, Freedman J, Garvry MB. Acute leukemia evolving from multiple myeloma and co-expressing myeloid and plasma cell antigens. Am J Hematol 34: 210, 1990.

5) Grogan TM, Durie BGM, Lomen C, et al. Delineation of a novel pre-B cell component in plasma cell myeloma: Immunochemical, immunophenotypic, genotypic, cytologic, cell culture, and kinetic features. Blood 70: 932, 1987.

6) Akashi K, Harada M, Shibuya T, et al. Simultaneous occurrence of myelomonocytic leukemia and multiple myeloma: Involvement of common leukemic progenitors and their developmental abnormality of lineage infidelity. J Cell Physiol 148: 446, 1991.

7) Kita K, Nakase K, Miwa H, et al. Phenotypical characteristics of acute myelocytic leukemia associated with the $\mathrm{t}(8 ; 21)(\mathrm{q} 22 ; \mathrm{q} 22)$ chromosomal abnormality: Frequent expression of immature B-cell antigen CD19 together with stem cell antigen CD34. Blood 80: 470, 1992.

8) Nosaka T, Kita K, Miwa H, et al. Cross lineage rearrangements in human leukemic B-precursor cells occur frequently with V-DJ rearrangements of IgH genes. Blood 74: 361, 1989.

9) Asou H, Tashiro S, Hamamoto K, Otsuji A, Kita K, Kamada N. 


\section{AMMoL in Multiple Myeloma}

Establishment of a human acute myeloid leukemia cell line (Kasumi-1) with 8;21 chromosome translocation. Blood 77: 2301, 1991.

10) Gonzalez F, Trujillo JM, Alexanian R. Acute leukemia in multiple myeloma. Ann Intern Med 86: 440, 1977.

11) Bergsagel DE, Bailey AJ, Langley GR, MacDonald RN, White DF, Miller AB. The chemotherapy of plasma-cell myeloma and the incidence of acute leukemia. N Engl J Med 301: 743, 1979.

12) Pedersen-Bjergaard J, Philip P. Cytogenetic characteristics of therapyrelated acute non-lymphocytic leukaemia, preleukaemia and acute myeloproliferative syndrome: Correlation with clinical data for 61 consecutive cases. Br J Haematol 66: 199, 1987.

13) Coltman CA, Dahlberg S. Treatment-related leukemia. N Engl J Med 322: 52, 1990.

14) Ludwig H, Pavelka M. Phagocytic plasma cells in a patient with multiple myeloma. Blood 56: 173, 1980.

15) Grogan TM, Durie BGM, Spier CM, Richter K, Vela E. Myelomonocytic antigen positive multiple myeloma. Blood 73: 763, 1989.

16) Greaves MF, Chan LC, Furley AJW, Watt SM, Molgaard HV. Lineage promiscuity in hemopoietic differentiation and leukemia. Blood 67: 1, 1986.

17) Epstein J, Xiao H, He X-Y. Markers of multiple hematopoietic-cell lineages in multiple myeloma. N Engl J Med 322: 664, 1990.

18) Kita K, Miwa H, Ohno T, Shirakawa S. Molecular genetical examinations of multiple myeloma and other B-cell malignancies. Acta Haematol Jpn 50: $1729,1987$.

19) Nakase K, Kita K, Otsuji A, et al. Diagnostic and clinical importance of interleukin-2 receptor alpha chain expression on non-T-cell acute leukaemia cells. Br J Haematol 80: 317, 1992.

20) Anderson KC, Bates MP, Slaughenhoupt B, Schlossman SF, Nadler LM. A monoclonal antibody with reactivity restricted to normal and neoplastic plasma cells. J Immunol 132: 3172, 1984. 